\title{
Serum PCT and CRP Levels in Upper Respiratory Tract Infections as a Marker of Infection
}

\author{
Preeti Chauhan, Archana Sood, Manisha Jain, Pradeep Dabla, Sanjay Sood
}

\begin{abstract}
Most of the upper respiratory tract infections are viral in origin and accounts for the most frequent cause of antibiotic misuse world over. Conventional test like microbiological culture for confirming bacterial etiology is not very sensitive. We evaluated the utility of biomarkers like procalcitonin (PCT), C-reactive protein (CRP) and total leukocyte count (TLC) to guide antibiotic treatment in such cases. Fifty patients were divided into two groups, those having acute suppurative tonsillitis $(n=40)$ and those having acute rhinosinusitis $(n=10)$ were included. Appropriate samples were processed for microbiological culture. Blood samples were taken for PCT, CRP and TLC estimation. Almost $34 \%$ of the patients were taking antibiotics at least 1 day prior to their consultation. Microbiological culture was positive only in $38 \%$ of cases. The levels of PCT were significantly higher in cases of acute suppurative tonsillitis as compared to rhinosinusitis. The PCT levels correlated well with CRP, TLC and degree of fever in tonsillitis cases. The levels of CRP correlated well with the TLC levels in rhinosinusitis cases. PCT and CRP levels were higher than the normal healthy population in our patients. They can be used as a marker for guiding antibiotic treatment in cases of upper respiratory tract infection of bacterial origin.
\end{abstract}

Keywords: Procalcitonin, C-reactive protein, Tonsillitis, Rhinosinusitis.

How to cite this article: Chauhan P, Sood A, J ain M, Dabla P, Sood S. Serum PCT and CR P Levels in Upper Respiratory Tract Infections as a Marker of Infection. Clin Rhinol An Int J 2013;6(1):1-4.

\section{Source of support $\mathrm{Nil}$}

Conflict of interest: None declared

\section{INTRODUCTION}

In primary care setting, upper respiratory tract infections (URIS) often presenting as sore throat and running nose remains a very common cause for hospital visit. ${ }^{1,2} \mathrm{M}$ any of such cases are treated empirically with antibiotics and other symptomatic medications without looking for etiology. This leads to misuse of antibiotics as most of the URIs are viral in origin and are usually self-limiting. A report by World Health Organization (WHO) indicates that for every 100 respiratory infection incidence, only 20 require antibiotic treatment. $^{2}$

A mong U RIs acute tonsillitis and rhinosinusitis are most commonly bacterial in origin and requires adequate antibiotic treatment for early reminiscence and for eradicating the bacterial pathogen from infected sinus in cases of sinusitis. ${ }^{3,4}$ The most accurate way of confirming an infectious cause would be bacteriological culture from the clinical sample. B ut the sensitivity of a microbiological culture is less and also it is time consuming so antibiotics are started in most of the patients presenting with simpleURIs by the general physician. This leads to overuse of antibiotics, which further compounds the development of resistance. ${ }^{5}$

Increased C-reactive protein (CRP) levels are being used by some physicians to guide for antibiotic treatment in cases of URIS. ${ }^{6}$ The level of procalcitonin (PCT) has been found to be raised in systemic bacterial infection but remain low in viral infection and inflammatory disease. ${ }^{7,8} \mathrm{~F}$ urther, $\mathrm{PCT}$ based therapeutic strategies have been show $n$ to substantially and safely reduce antibiotic use in patients less severe lower respiratory tract infection or chronic obstructive lung disease. ${ }^{9,10}$ The question is whether inflammatory markers such as PCT and CRP are effective in initiating the antibiotic treatment as a primary diagnostic tool in cases of URIS especially those of infectious origin.

There are limited studies on the evaluation of PCT as a marker of localized infection as is seen in cases of URIs. Thus, our study planned to evaluate the role of PCT and CRP in patients with acute tonsillitis and rhinosinusitis for guiding antibiotic treatment.

\section{MATERIALS AND METHODS}

The study was performed prospectively at the B alaji A ction Hospital, New Delhi, a tertiary care hospital and was approved by the ethical committee of the hospital. A $n$ informed consent was obtained from all the 50 patients included in the study. The patients were divided into two groups based on the clinical criteria as having acute suppurative tonsillitis $(n=40)$ and rhinosinusitis $(n=10)$. The study format was observational and not interventional, none of the subjects were denied any treatment and they were treated as per the set protocols of the hospital.

\section{Selection Criteria}

Diagnosis of acute suppurative tonsillitis was based on redness of tonsils, pus point on tonsils, pain, difficulty in swallowing with fever $\left(>38.5^{\circ} \mathrm{C}\right)$ along with enlarged cervical lymph nodes. Diagnosis of rhinosinusitis was based on the presence of nasal blockage, congestion, postnasal drip, pressure and facial pain accompanied by radiological investigations according to the criteria of European Rhinosinusitis Committee. ${ }^{11}$ 
All patients were evaluated for their complaints and a detailed medical history including the demographic details was recorded in a performa. Local and systemic examination was done as per the protocols. A ppropriate samples which included tonsillar swabs in case of acute suppurative tonsillitis and aspirated pus from medial meatus from those with rhinosinusitis were collected for bacteriological culture and the patients were started on antimicrobial treatment.

\section{Sample Collection and Analysis}

The samples for bacteriological culture were processed as per standard protocols. The identification of pathogens was performed by standard microbiological methods and the automated A PI system (B ioM erieux, France). Susceptibility to antimicrobial agent was determined by the disk diffusion method as per the clinical and laboratory standards institute (CLSI) guidelines.

Blood samples were obtained from all patients for complete blood count including total leukocyte count (TLC), CRP and PCT. PCT was measured semiquantitatively by a rapid immunochromatographic kit as per the manufacturer's recommendations (BRAHM S PCT-Q test). The level of $\geq 0.5 \mathrm{ng} / \mathrm{ml}$ for PCT was taken as significant. CRP was measured by Turbox-immunonephelometry method (Orion diagnostic) along with 2-level control provided by manufacturer. CRP value more than $10 \mathrm{mg} / \mathrm{l}$ was regarded as elevated.

\section{Statistical Analysis}

Statistical analysis was carried out using SPSS for windows 19.0 software (SPSS Inc., Chicago, IL, USA). Data are expressed in mean and range. The levels of PCT and CRP were compared between the two groups. Normally distributed data groups were compared by Student's t-test and correlation was computed using Pearson's correlation coefficient. For data that was not normally distributed nonparametric tests, W ilcoxon signed rank and Spearman's rank coefficient test were applied ( $p$-value $<0.05$ was considered significant).

\section{RESULTS}

The study comprised of 50 patients, 32 males and 18 females with a median age of 33 years (range: 16-48 years). Fever upon admission was seen in all the patients $(100 \%)$. A Imost $34 \%$ (17 out of 50 ) patients were taking antibiotic for at least 1 day prior to first examination.

Of the 50 samples sent for culture sensitivity al most $62 \%$ samples were sterile and only 38\% (19/50) samples were culture positive. Streptococcus species was the most common bacterial agent isolated in 15 cases (30\%) whereas in another four patients Escherichia coli was isolated. Out of 10 patients of rhinosinusitis only $30 \%$ (three patient) showed a positive culture and 16 of 40 patients (40\%) of acute tonsillitis showed positive culture.

The mean level of CRP, PCT and TLC in both the groups are as shown in Table 1 . The level of PCT was significantly higher in cases of acute suppurative tonsillitis as compared to rhinosinusitis cases ( $p$-value $<0.05$ ) whereas the level of CRP was significantly higher in cases of rhinosinusitis $(p<0.01)$. No significant difference was noticed in the TLC count between both the groups.

\begin{tabular}{|c|c|c|c|}
\hline Biomarkers & $\begin{array}{l}\text { Acute suppurative } \\
\text { tonsillitis }(n=40)\end{array}$ & $\begin{array}{l}\text { Rhinosinusitis } \\
\quad(n=10)\end{array}$ & $p$-value \\
\hline $\begin{array}{l}\text { PCT } \\
\text { CRP } \\
\text { TLC }\end{array}$ & $\begin{aligned} 1.8 & \pm 0.78 \\
28.36 & \pm 12.47 \\
18,900 & \pm 6,500\end{aligned}$ & $\begin{aligned} 0.8 & \pm 0.2 \\
44.8 & \pm 14.9 \\
16,000 & \pm 4.2\end{aligned}$ & $\begin{array}{l}<0.05 \\
<0.01 \\
>0.5\end{array}$ \\
\hline
\end{tabular}

Pearson's correlation test was done to find out the correlation between different parameters predicting infection. It was seen that blood PCT level showed significant correlation with TLC ( $r s=0.461, p<0.01)$, CRP ( $r s=0.697, p<0.01)$ and body temperature ( $r s=0.630$, $p<0.01$ ) in cases of tonsillitis whereas in cases of rhinosinusitis significant correlation was seen only between CRP levels and TLC ( $r s=0.674, p<0.05)$.

\section{DISCUSSION}

U pper respiratory infections remain the most frequent cause of visit to a physician or even the hospitals. ${ }^{1}$ They also remain a very common cause of misuse of antibiotics as most of the URIS are viral in origin. There is a decline in the development of newer antibiotics in the market. ${ }^{5} \mathrm{H}$ ence, there is a need to develop valid tools to assist the clinicians to control the development of resistance by limiting excessive use of antibiotic. The gold standard for differentiating bacterial from viral causes of URIs is microbiological culture but the sensitivity is low. Etiological differentiation based on clinical symptom score and radiological investigation have not proven to be valid. ${ }^{12,13}$ Limited studies are available regarding the use of these biomarkers in patients presenting with acute tonsillitis and rhinosinusitis which are very prevalent community infection.

We studied biomarkers such as CRP, PCT and TLC to see the diagnostic utility of these markers in such cases to guide antibiotic treatment.

PCT is a prohormone with 116 amino acids and molecular weight of $13 \mathrm{kDa} .{ }^{14,15}$ In the normal subjects the 
circulating PCT concentration are low $(<0.5 \mathrm{ng} / \mathrm{ml}) .{ }^{16} \mathrm{M}$ any studies have proven the role of PCT in diagnosing systemic infection and even lower respiratory tract infections. ${ }^{17-19}$ The level of PCT increases with the onset of bacteremia in response to bacterial endotoxin and other mediator such as TNF- $\alpha, I L-2, I L-6.17,18$ The exact role of PCT in inflammation and the host response is not fully understood but in severe infection serial measurement of PCT has been shown as a predictor of mortality. ${ }^{20,21}$

CRP is an acute phase protein that rises at the time of infection or inflammation. ${ }^{22}$ It is produced by hepatocyte within 4 to 6 hours after onset of tissue injury. It is often considered as a nonspecific marker for predicting inflammatory conditions in the body. ${ }^{22}$

W e observed that the mean level of PCT was $1.8 \pm 0.78$ $\mathrm{ng} / \mathrm{ml}$ in cases of acute tonsillitis much higher than the levels found in normal population $(<0.5 \mathrm{ng} / \mathrm{ml})$. The rising levels of PCT correlated well with other markers such as CRP, TLC and fever. That is with rising PCT levels the levels of $C R P$ and $T L C$ increased. The levels also correlated well with the disease severity as predicted by the rise of body temperature seen in cases of acute suppurative tonsillitis.

In case of rhinosinusitis, the mean level of PCT was $0.8 \pm 0.2 \mathrm{ng} / \mathrm{ml}$ marginally higher than the normal population. The levels of PCT did not correlate well with other markers such as CRP and TLC. A Ithough it was observed that as the CRP levels increased the TLC also increased.

In the present study, PCT levels were higher than the normal healthy population in cases of both acute Suppurative tonsillitis as well as rhinosinusitis. This is in contrast to few studies having show $n$ a negative correlation between PCT levels and localized infection such as that seen in cases of URIS. ${ }^{22,23}$ O ur study is in agreement to few studies having shown the utility of PCT for guiding antibiotic treatment in cases of lower and URIs. ${ }^{24,25}$ It was seen that restricting antibiotics in a patient at a mean PCT level of $<0.25 \mathrm{ng} / \mathrm{ml}$ and advising antibiotic treatment in patients with PCT $>0.25 \mathrm{ng} / \mathrm{ml}$ lead to almost $72 \%$ decrease in antibiotic prescription rate in both upper and lower respiratory tract infections. ${ }^{25}$

The limitation of our study was that bacterial etiology could not be proved in $62 \%$ of the cases. This could be because 17 (34\%) patients had started antibiotic treatment prior to sample collection so despite being bacterial in origin the culture might have turned negative. This could be also because other fastidious organisms like Mycoplasma pneumoniae and Neisseria gonorrhoeae were not screened for which also accounts for few cases of acute tonsillitis and rhinosinusitis.

\section{CONCLUSION}

In view of increasing antimicrobial resistance worldwide, it seems worthwhile to limit the use of antibiotics by using appropriate biomarkers to differentiate the bacterial vs viral etiology in one of the most common infections encountered in clinical practice such as URIS. The present study highlights the importance of using PCT levels as a marker for deciding antibiotic use in patients of URIs. However, the results are preliminary, not many studies are available supporting this finding a larger study involving more number of patients, and possibly covering different geographical areas would be helpful to address these issues.

\section{REFERENCES}

1. Goetzel RZ, H awkins K, Ozminkowski RJ, W ang S. The health and productivity cost burden of the 'top 10' physical and mental conditions affecting six large US employers in 1999. J Occup Environ M ed 2003;45:5-14.

2. WHO report on infectious disease: Overcoming antimicrobial resistance. Geneva: W HO, 2000. A vailable from: www.who.int/ infectious-disease-report/2000. A ccessed on 10th Nov 2012.

3. K lein J O. Current issues in upper respiratory tract infections in infants and children: R ationale for antibacterial therapy. Pediatr Infect Dis J 1994;13(1):S5-9.

4. Jain N, Lodha R, Kabra SK. U pper respiratory tract infections. Ind J Ped 2001;68(12):1135-38.

5. B oucher HN, Talbot GH, B radley JS, et al. B ad bugs, no drugs: No ESKA PE! A n update from the infectious Diseases Society of A merica. Clin Infect Dis 2009;48(1):1-12.

6. A ndre M, O denholt I, Schwan A, et al. U pper respiratory tract infection in general practice: Diagnosis, antibiotic prescribing, duration of symptoms and use of diagnostic tests. Scand J Infect Dis 2002;34(12):880-86.

7. M eisner M. B iomarkers of sepsis: Clinically useful? Curr O pin Crit Care 2005;11:473-80.

8. Stolz D, Christ-Crain M, Gencay M M, et al. Diagnostic value of signs, symptoms and laboratory values in lower respiratory tract infection. Swiss M ed W kly 2006;136: 434-40.

9. Christ-Crain $M$, Jaccard-Stolz D, Bingisser $R$, et al. Effect of procalcitonin guided treatment on antibiotic use and outcome in lower respiratory tract infections: Cluster randomized, singleblinded intervention trial. Lancet 2004;363:600-07.

10. Stolz $D, C$ hrist- $C$ rain $M$, B ingisser $R$, et al. A ntibiotic treatment of exacerbations of COPD: A randomised, controlled trial comparing procal citonin-guidance with standard therapy. Chest 2007;131:9-19.

11. Rhinosinusitis task force committee, 1997. Report of the R hinosinusitis Task Force Committee M eeting. Otolaryngol Head Neck Surg 1996;117:s1-68.

12. LittleP. Penicillin for acute sore throat in children: Randomized double blind trial commentary: More valid criteria may be needed. B M J 2003;327(7427):1327-28.

13. Butler CC, Simpson S, Wood F. General practitioner's perception of introducing near-patient testing for common injections into routine primary care: A qualitative study. Scand J Prim Health Care 2008;26(1):17-21. 
14. Becker KL, Nylen ES, White JC, Muller B, Snider RH. Procalcitonin and the calcitonin gene family of peptides in inflammation, infection and sepsis: A journey from calcitonin back to its precursors. J Clin Endocrinol M etab 2004:89(4): 1512-25.

15. Snider RH, Nylen ES, Becker KL. Procalcitonin and its compound peptides in systemic inflammation: I mmunochemical characterization. J Investig M ed 1997;45(9):552-60.

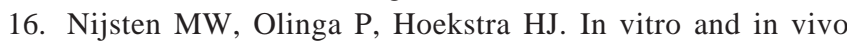
stimulation of procalcitonin by $\mathrm{TNF} \alpha$ and IL-6. J A nasthes Intensiv Ther 2001;2:58-60.

17. Oberhoffer M, Stonans I, Russwurm S, et al. Procalcitonin expression in human peripheral blood mononuclear cells and its modulation by lipopolysaccharides and sepsis-related cytokines in vitro. J L ab Clin M ed 1999;134:49-55.

18. Jensen JU, H eslet L, J ensen TH, E spersen K, Steffensen $P$, T vede $M$. Procalcitonin increases in early identification of critically ill patients at high risk of mortality. Crit Care Med 2006;34(10):2596-602.

19. Holm A, Pedersen SS, Nexoe J, et al. Procalcitonin versus $C$-reactive protein for predicting pneumonia in adults with lower respiratory tract infection in primary care. $\mathrm{Br}$ J Gen Pract 2007;57(540):555-60.

20. M eisner $\mathrm{M}, \mathrm{A}$ dina $\mathrm{H}$, Schmidt J. Correlation of procalcitonin and $\mathrm{C}$-reactive protein to inflammation, complications and outcome during the intensive care unit course of multiple trauma patients. Crit Care 2006;10:1-10.

21. M orgenthaler NG, Struck J, Fischer Schulz C, Seidel-M ueller $E$, B eier W, B ergmann A. Detection of procalcitonin (PCT) in heal thy controls and patients with local infection by a sensitive IL M A. Clin Lab 2002;48:263-70.

22. Korppi M, Remes S, H eiskanen-K osma T. Serum Procalcitonin concentrations in bacterial pneumonia in children: A negative result in primary healthcare settings. Pediatr Pulmonol 2003;35(1):56-61.
23. K ofteridis DP, Samonis G, K aratzanis D, et al. C-reactive protein and serum procalcitonin levels as markers of bacterial upper respiratory tract infections. A m J Infect D is 2009;5(4):292-97.

24. Briel $M$, Schuetz $P, M$ ueller $B$, et al. Procalcitonin guided antibiotic use versus a standard approach for acute respiratory tract infections in primary care. Arch Intern Med 2008;168(18):2000-07.

25. B urkhardt $\mathrm{O}$, Ewig $\mathrm{S}, \mathrm{H}$ aayen $\mathrm{U}$, et al. Procal citonin guidance and reduction of antibiotic use in acute respiratory tract infection. Eur Respir J 2010;36(3):601-07.

\section{ABOUT THE AUTHORS}

\section{Preeti Chauhan}

A ssistant Professor, Department of B iochemistry, ESIC D ental College and Hospital, Rohini, New Delhi, India

\section{Archana Sood}

Associate Professor and Head, Department of Biochemistry, ESIC Dental College and Hospital, Rohini, N ew Delhi, India

\section{Manisha Jain}

A ssistant Professor, Department of M icrobiology, ESIC Dental College and Hospital, Rohini, New Delhi, India

\section{Pradeep Dabla}

A ssistant Professor, D epartment of B iochemistry, Chacha N ehru Bal Chikitsalaya, Shastri Park, New Delhi, India

\section{Sanjay Sood (Corresponding Author)}

Senior Consultant, D epartment of ENT, H oly Family H ospital, New Delhi, India, Phone: 9810219343, e-mail: sanjaysood_doc@live.com 